\title{
A COMPARATIVE EVALUATION OF FRACTURE RESISTANCE OF ENDODONTICALLY TREATED TEETH RESTORED WITH THREE DIFFERENT POST AND CORE SYSTEMS AND TWO DIFFERENT LUTING AGENTS - AN INVITRO STUDY
}

\author{
Neena Chandran., Noushad MC and Biji Balan
}

\author{
Department of Conservative Dentistry and Endodontics, Kannur Dental College, Kannur, Kerala, India \\ DOI: http://dx.doi.org/10.24327/ijrsr.2017.0804.0279
}

\section{ARTICLE INFO \\ Article History: \\ Received $18^{\text {th }}$ February, 2017 \\ Received in revised form $10^{\text {th }}$ \\ March, 2017 \\ Accepted $06^{\text {th }}$ April, 2017 \\ Published online $28^{\text {th }}$ May, 2017}

\section{Key Words:}

Cast post core, Glass fibre post, zirconia post, fracture resistance.

\begin{abstract}
Purpose: To compare fracture resistance and primary mode of failure of endodontically treated teeth with three different posts systems and two variant luting agents.

Materials and Methods: Root canal treatment was performed on 40 maxillary incisors and samples were divided into 4 groups. For three experimental groups post space preparation was done and teeth were restored with cast post-core (Group B), prefabricated glass fibre post (everStick post) with composite core (Group C) and prefabricated zirconia posts with composite core (Group D). Control group (A) samples were selected with intact coronal structure. Post space was prepared in all samples. Two type of luting cements dual cure resin cement (Luxacore Z) and glass ionomer cement (Fuji I, GC) were used for post cementation. The core was standardized to $4 \mathrm{~mm} \times 5 \mathrm{~mm}$. Prepared samples were subjected to compressive load of $0.5 \mathrm{~mm} / \mathrm{min}$ at $135^{\circ}$ angulation. The load at which fracture occurred and fracture mode were analysed statistically by one way ANOVA, post-hoc tukey test and chi-square test.

Results: The findings showed statistically significant difference between failure loads. The mean load required to fracture glass fibre was highest $(711 \mathrm{MPa})$ and least for control group (231MPa). The glass fibre posts and zirconia posts showed favorable fracture.

Conclusion: The results concluded that endodontically treated teeth without post core system showed least fracture resistance signifying need to reinforce tooth. Use of glass fibre post (everStick post) showed highest mean fracture resistance regardless of luting agent.
\end{abstract}

Copyright (C) Neena Chandran et al, 2017, this is an open-access article distributed under the terms of the Creative Commons Attribution License, which permits unrestricted use, distribution and reproduction in any medium, provided the original work is properly cited.

\section{INTRODUCTION}

The restoration of endodontically treated tooth is a challenging task that involves treatment of significant tooth structure loss. ${ }^{1}$ The endodontically treated tooth must be restored such that it will resist masticatory forces acting in vertical and lateral direction without being prone to fracture. To reinforce treated tooth, post and core are preferred which also ensures coronoradicular stabilization. ${ }^{2}$

The choice of the post is dependent on external configuration and morphology of root; diameter, surface, geometrical configuration of dowel and materials used to fabricate these systems.4 The endodontic posts can be metallic and nonmetallic or stiff and flexible. ${ }^{3}$

The cast post-and-core has been considered as the gold standard because of its superior success rate. ${ }^{4}$ The choice of restoring endodontically treated tooth is guided by strength and esthetics.7 Various tooth colored posts are available like zirconium coated carbon fiber post, all zirconium Cerapost, fibre reinforced light post and glass fibre post. ${ }^{3}$ The prefabricated dowels are reported to be more flexible than cast metal dowel and allow better distribution of forces resulting in smaller number of root fractures.

The quality of cement is fundamental for post retention. However there is no consensus in the literature as to the superiority of one cement compared to the other. There are several luting agents such as zinc phosphate, GIC, resin cement. ${ }^{5}$ The effect of the cement type on the retention of post and on fracture resistance of endodontically treated teeth has been investigated extensively. The use of resin cement has been found to significantly increase retention of posts and fracture resistance of the tooth compared with other cements.

In this study, three types of post have been used to restore endodontically treated teeth namely cast metal post and core, individually formable and unpolymerized glass fiber post (GC everStick) and zirconia post. Hence the purpose of this study is to evaluate the fracture resistance of cast post and core, prefabricated zirconia post and prefabricated glass fibre posts 
cemented with varying luting agents such as resin cement and GIC.

\section{MATERIALS AND METHODS}

A total of forty single rooted maxillary central incisors were collected from the Department of Oral and Maxillofacial Surgery, Kannur dental college and placed in formalin solution for disinfection. After disinfection the samples were maintained in normal saline solution to prevent dehydration. Root canal treatment was carried out on all specimens and obturation was done by lateral condensation technique using 60-size guttapercha (Dentsply, Addlestone, Surrey, UK) as master cone. The selected teeth were randomly assigned into four experimental groups and two subgroups.

- Group A : CONTROL GROUP (10 teeth)

- Group B : CAST METAL POST

Resin (5 teeth)

GIC (5 teeth)

- Group C: PREFABRICATED GLASS FIBER POST

Resin (5 teeth)

GIC (5 teeth)

- Group D: PREFABRICATED ZIRCONIA POST

Resin (5 teeth)

GIC (5 teeth)

The specimen teeth in group B, C and D were decoronated with a fine grit diamond disc. to standardize root length approximately $16 \mathrm{~mm}$. Gutta percha was removed using no. \#2 Gates Glidden drill until depth of $10 \mathrm{~mm}$ in all the experimental groups except group A (control group). The post preparations were standardized through flaring with Peeso reamer upto no \# 4.

\section{Post Fabrication}

In group B a direct technique was used to fabricate a post core pattern with inlay wax (Green Inlay Wax: Medium, GC Corporation, Tokyo, Japan).The pattern was casted with Type IV cobalt- chromium base metal alloy using a lost wax technique. The post was then sand blasted for 3 - 4 seconds with $50 \mu \mathrm{m}$ aluminum oxide powder and then cleaned with distilled water to improve the adhesion. Prefabricated posts were used in group C and D.

\section{Post Cementation}

Prior to cementation, the posts were trial seated to ensure complete seating to a depth of $10 \mathrm{~mm}$. In group $\mathrm{C}$, prefabricated posts were cut with a scissor to desired length (i.e, with an excess of $4 \mathrm{~mm}$ to retain the core). In group D the posts were cut with a diamond disc. Each post space were then irrigated with $5 \mathrm{ml}$ of saline and dried with paper points.

For those samples luted with dual cure resin cement, the post space was etched with $37 \%$ phosphoric acid (Total Etch; Ivoclar Vivadent) for $15 \mathrm{sec}$, rinsed with distilled water for 15 seconds and dried with paper points. Bonding agent was applied within the canal with micro brush and cured for 20seconds. The resin cement (Luxacore Z, DMG, America) was applied with a lentulospiral. The post was seated into the canal. Excess cement was removed using a sable brush. The cement was then light cured for 40 seconds.In group $\mathrm{C}$, as the post is supplied in a pre-polymerised form, post and the cement were light cured for 40 seconds by directing the light perpendicular to the post.

In those samples luted with GIC, the cement was applied within the post space with lentulospiral. The post was then seated and finger pressure was maintained. For the samples in group $\mathrm{C}$, the posts were light cured before cementation with GIC.

\section{Core Build Up}

The core was standardized to $4 \mathrm{~mm}$ length from incisal edge to cervical region and $5 \mathrm{~mm}$ width. In group A, straight fissure bur was used to standardize the core. In group B, Type IV cobaltchromium base metal alloy was used to fabricate the core. The coronal portion of the samples in group $\mathrm{C}$ and $\mathrm{D}$ were fabricated with dual cure resin cement (Luxacore $\mathrm{Z}, \mathrm{DMG}$ America) and polymerized.

\section{Procedure for Testing Fracture Resistance}

Each specimens were mounted in an acrylic block of size $19 \mathrm{~mm}$. The acrylic block with specimens were mounted on a Universal Testing Machine. The compressive load was applied with $1 \mathrm{~mm}$ diameter compressive head at an angle of $135^{\circ}$ to the long axis of the tooth. The force was applied on the palatal slope at a rate of $0.5 \mathrm{~mm} / \mathrm{min}$ until visible or audible evidence of fracture was shown. The force at which fracture occured was measured in MPa. Descriptive data were collected and analysed. The results were evaluated statistically using one way ANOVA, post- hoc tukey and Chi-square test.

The analysis of variance test (FIG 1) was used to compare the mean differences between the groups to evaluate fracture resistance. The $\mathrm{P}$ value calculated is $<0.05$ which indicates the statistical significance. In all the tested samples control group exhibited the lowest fracture resistance. The glass fiber post luted with resin cement exhibited highest fracture resistance among the all four groups. Among the experimental groups lowest fracture resistance was recorded for group B subgroup B with cast post and core luted with glass ionomer cement.

Fig 1

\begin{tabular}{cccccc}
\hline & $\begin{array}{c}\text { Number } \\
\text { of values }\end{array}$ & Mean & $\begin{array}{c}\text { Std. } \\
\text { Deviation }\end{array}$ & F & P Value \\
\hline Control & 10 & 231.00 & 14.674 & & \\
Cast - Dual Cure Resin & 5 & 379.40 & 4.099 & & \\
Cast - GIC & 5 & 367.40 & 3.782 & & \\
Glass Fibre - Dua Cure Resin & 5 & 711.00 & 3.808 & & \\
GLASS FIBRE - GIC & 5 & 685.40 & 5.771 & $3.083 \mathrm{E} 3$ & $<0.05$ \\
Zirconia - Dual Cure Resin & 5 & 623.60 & 4.393 & & \\
Zirconia - GIC & 5 & 574.40 & 4.827 & & \\
\hline
\end{tabular}

The post-hoc tukey test (FIG 2) was used for multiple comparison within the groups. On analysis the $\mathrm{P}$ value for each group comparison is less than 0.05 which shows high significance. The chisquare test were used to compare the four groups and two subgroups for the mode of faliure. Here the probability value is less than 0.05 and it indicates the highly significant statistical result. The results showed that all samples in Group C and Group D had restorable fractures than remaining groups. 
Fig 2

\begin{tabular}{ccc}
\hline Control & $\begin{array}{c}\text { Restorable } \\
\text { Fracture }\end{array}$ & $\begin{array}{c}\text { Non-Restorable } \\
\text { Fracture }\end{array}$ \\
\hline Cast - Dual Cure Resin & 0 & 10 \\
Cast - GIC & 0 & 5 \\
Zirconia - Dual Cure Resin & 0 & 5 \\
Zirconia-GIC & 5 & 0 \\
Glass Fiber - Dual Cure Resin & 5 & 1 \\
Glass Fiber - GIC & 5 & 0 \\
\hline
\end{tabular}

\section{DISCUSSION}

To restore the strength of badly broken root canal treated teeth, an ideal solution is the use of a post and core which protects the weakened tooth. ${ }^{6}$ The evaluation of whether a post is needed depends on how much natural tooth substance remains to retain a core buildup and support the final restoration after caries removal and endodontic treatment are completed. ${ }^{7}$ The criteria for an endodontically treated tooth requiring a post is that the minimum length of remaining solid tooth equal the sum of the biologic width $(2.5 \mathrm{~mm})$, the ferrule length $(2 \mathrm{~mm})$, the apical seal $(4 \mathrm{~mm})$ and the post length (i.e, $8.5 \mathrm{~mm}+$ post length). ${ }^{8}$

The post/dowel selection is influenced by several factors which includes amount of coronal tooth structure, tooth anatomy, position of the tooth in the arch, root length, root width, canal configuration, functional requirements of the tooth, torquing force, stresses, development of hydrostatic pressure, post design, post material, material compatibility, bonding capability, core retention, retrievability, esthetics and crown material. ${ }^{9}$

Recently, the material of choice for restoration of root filled teeth has changed from very rigid materials to materials with mechanical characteristics similar to dentine. ${ }^{10}$ These newer systems have paid attention on physical properties, such as modulus of elasticity (rigidity) to reduce stress concentrations within the root canal and reduce the incidence of fractures. An additional feature of the newer posts has been the esthetics with composite core materials.

EverStick post is a recently introduced glass fiber post consisting of unidirectional E-glass and unpolymerized BisGMA matrix, and it has elastic modulus similar to dentin. This post is composed of glass fibres embedded in an unpolymerized resin matrix. The post is available in a soft form and hardens on polymerization with light. An enamel bonding agent without solvent like acetone can penetrate into and partly solve unpolymerized resin matrix monomers, thus allowing to bond with resin cements. In addition, EverStick Post can be bonded each other and trimmed suitably for adaptation to root canal. $^{8}$

In the current study, the fracture resistance of endodontically treated incisors was evaluated when using three post systems and two luting agents. Cast post and core, prefabricated glass fibre post with composite core, and prefabricated zirconia post with composite core were used with two different type of luting agents i.e. resin cement and glass ionomer cement. These cements were chosen as G.I.C. bonds chemically to tooth structure and resin cement is gaining recognition as various investigators have reported advantages related to their use. ${ }^{11}$ The resin cements are highly resistant to moisture and therefore become highly durable cements.
Maxillary central incisor was selected as it is the most vulnerable tooth to trauma because of its position and thereby, requires maximum restoration in terms of post core. The loading angle of $135^{\circ}$ from palatal to labial was selected on the basis that it simulates the average angle of contact between maxillary and mandibular incisors in Class I occlusion and is a test of function. ${ }^{12}$

From the data it is observed that group A i.e. control group demonstrated the least mean fracture resistance values as compared to experimental groups. The results of this study are consistent with Kantor and Pines ${ }^{13}$, Robbins ${ }^{14}$ who recommended post and core to increase the fracture resistance. Among the experimental groups, group $\mathrm{C}$ (EverStik posts) exhibited the highest mean fracture load. This could be explained as fibre posts and composite cores possess a modulus of elasticity much better matched to that of dentin. This creates a mono-block of dentin-post-core system through the dentinbonding. This inturn allows better distribution of applied forces evenly along the length of the post and root. Therefore, the excessive loads would be absorbed. ${ }^{15}$ The above results are also consistent with Omar Ahmed ${ }^{16}$ who demonstrated the highest mean fracture resistance values for everStick post. However these results are contrary to the findings of Dayalan $\mathrm{M}$ et $a l^{17}$ who compared the fracture strength of the zirconia oxide posts and prefabricated glass fiber post and concluded that zirconium oxide posts showed higher fracture strength when compared to glass fibre posts. Of the experimental group, cast post and core showed least fracture resistance. The higher modulus of elasticity of cast metal compared with dentin would have lead to the stress concentrations, and might be responsible for root fracture at lower fracture loads. ${ }^{18}$ Rigid metallic posts were responsible for stress concentration at the apical end and the coronal third of the canal wall, resulting in catastrophic vertical root fractures. ${ }^{19}$ This finding is consistent with Kaur et al. who demonstrated higher fracture with cast post compared to glass fibre post and composite core. ${ }^{20}$ Our results confirm findings reported by Pasqualin et al. ${ }^{21}$ and Verrisimo et $a l^{22}$ that the cast metal posts have a lower value of fracture resistance than fibre posts. This study also supports the findings by Makade et al. who reported in an invitro study that, glass fiber post is better compared to metal posts.

This study also concluded that the fracture resistance of zirconia post is lower than Everstick post but higher than cast post and core. This may be because the modulus of elasticity in FRC posts is similar to tooth tissue; hence, post failure under critical loads should occur before root fracture. This result is in agreement with the invitro study by Abduljabbar $\mathrm{T}$, which concluded that fracture resistance of zirconium custom posts was higher than fiber posts and the cast post-cores. ${ }^{23}$ The number of repairable fractures in group $\mathrm{C}$ (fibre posts)and Group D (zirconia posts) was significantly greater than that of any other group, as the type of failure that occurred were primarily post and core fractures that potentially allow retreatment of the tooth. This may be because the individually formed posts provide fibre location closer to the outermost surface of the root where the highest functional stresses are located. ${ }^{24}$

The samples in Group B (cast post and core) showed non repairable fractures. In a similar study by Martinez-Insua et al tooth fractures were observed in $91 \%$ of the specimens restored 
with cast post and core. ${ }^{25}$ Dean et al. in an in vitro study observed that $50 \%$ of teeth had root fracture with cast post. ${ }^{26}$ The results of present study are consistent with Sirimai and Sidoli demonstrating no root fractures for fibre post i.e. restorable fractures. ${ }^{27}$ In this study the fibre post showed core fracture. Makade et al. found that teeth restored with cast post and core found to have root fracture whereas glass fibre posts demonstrated only core fracture. ${ }^{3}$ Akkayan and Gulmez in an invitro study concluded that zirconia posts induced more catastrophic root fractures, while teeth restored with fibre posts were less prone to fracture than teeth restored with zirconia posts. ${ }^{18}$

In the present study, groups with the resin luting system showed considerably higher mean fracture loads than those with glass ionomer cement. The statistical analysis also revealed significant difference between the groups with different luting cements. The results indicate that adhesive composite resin luting systems provided additional fracture resistance to metallic post.

Of the two types of nonmetallic posts used in this study, the EverStick post luted with resin cement was associated with the highest fracture forces. This could be due to the multiphase polymer matrix of these types of posts consisting of both linear and cross-linked polymer phases (semi interpenetration polymer network, semi-IPN). The monomers of the adhesive resins and cements can diffuse into the linear polymer phase, swell it, and by polymerization, form interdiffusion bonding resulting in monoblock effect. This will result in reduced stress formation at post/dentin and post/cement interfaces. The zirconia posts were supplied in a hardened form (with prepolymerized monomer), which might have reduced their potential for bonding to the resin cement and thus might have allowed relatively lower fracture forces than Everstick posts.

Therefore from the above studies it can be concluded that the fibre post has characteristics simulating natural dentinal structure than any other previously used post and it acts as a shock-absorber, dissipating much stresses on the finished restoration with small fraction forces to dentinal walls thus demonstrating restorable fractures. The composite core has exceptional adaption and forms strong bond to remaining tooth structure, bondable posts, resin cements, and eventually the final restoration creating the monoblock. In addition it is esthetic, simple and predictable.

\section{CONCLUSION}

According to the findings and within the limitations of the study, it was concluded that

1. The endodontically treated teeth without post core system showed the least fracture resistance demonstrating the need to reinforce the tooth.

2. Teeth restored with glass fibre post showed highest fracture resistance.

3. Teeth restored with cast post-and-core showed fracture of the tooth.

4. A more favorable mode of failure, through composite cores, was observed in teeth restored with glass fibre posts and zirconia posts making them more amenable to retreatment.

\section{References}

1. Alhashim NS, Al-Moaleem MM, Al-attas HA. Tooth Colored Post System: Review of Literature. International Journal of Contemporary Dentistry. 2013; 4(1).

2. Jhavar N, Bhondwe S, Mahajan V, Dhoot R. Recent Advances in Post Systems: A Review. Journal of Applied Dental and Medical Sciences. 2015; 1:3.

3. Makade CS, Meshram GK, Warhadpande M, Patil PG. A comparative evaluation of fracture resistance of endodontically treated teeth restored with different post core systems-an in-vitro study. The journal of advanced prosthodontics. 2011; 3(2):90-5.

4. Bergman B, Lundquist P, Sjo U. Restorative and endodontic results after treatment with cast posts and cores. The Journal of prosthetic dentistry. 1989; 61(1):10-5.

5. Bonfante G, Kaizer OB, Pegoraro LF, Valle ALd. Tensile bond strength of glass fiber posts luted with different cements. Brazilian Oral Research. 2007; 21(2):159-64.

6. Wadhwani $K$, Jindal $R$, Srivastava $S$, Nigam $P$. Comparative Evaluation of Fracture Resistance of Various Post Systrems â€-An In Vitro Study. Journal of Conservative Dentistry. 2003; 6(2):56.

7. Cheung W. A review of the management of endodontically treated teeth. Post, core and the final restoration. Journal of the American Dental Association (1939). 2005; 136(5):611-9.

8. Kim J-H, Park S-H, Park J-W, Jung I-Y. Influence of post types and sizes on fracture resistance in the immature tooth model. Journal of Korean Academy of Conservative Dentistry. 2010; 35(4):257-66.

9. Fernandes AS, Dessai GS. Factors affecting the fracture resistance of postcore reconstructed teeth: a review. The International journal of prosthodontics. 2001; 14(4):35563.

10. Eskitaşcıoğlu G, Belli S, Kalkan M. Evaluation of two post core systems using two different methods (fracture strength test and a finite elemental stress analysis). Journal of Endodontics. 2002; 28(9):629-33.

11. Chan FW, Harcourt JK, Brockhurst PJ. The effect of post adaptation in the root canal on retention of posts cemented with various cements. Australian dental journal. 1993; 38(1):39-45.

12. Goto Y, Nicholls JI, Phillips KM, Junge T. Fatigue resistance of endodontically treated teeth restored with three dowel-and-core systems. The Journal of prosthetic dentistry. 2005; 93(1):45-50.

13. Kantor ME, Pines MS. A comparative study of restorative techniques for pulpless teeth. The Journal of prosthetic dentistry. 1977; 38(4):405-12.

14. Robbins JW. Restoration of the endodontically treated tooth. Dental Clinics of North America. 2002; 46(2):367-84.

15. Rosentritt M, Fürer C, Behr M, Lang R, Handel G. Comparison of in vitro fracture strength of metallic and tooth-coloured posts and cores. Journal of Oral Rehabilitation. 2000; 27(7):595-601. 
16. Abo El-Ela OA, Atta OA, El-Mowafy O. Fracture resistance of anterior teeth restored with a novel nonmetallic post. Journal (Canadian Dental Association). 2008; 74(5):441.

17. Dayalan M, Jairaj A, Nagaraj K, Savadi RC. An evaluation of fracture strength of zirconium oxide posts fabricated using CAD-CAM technology compared with prefabricated glass fibre posts. The Journal of Indian Prosthodontic Society. 2010; 10(4):213-8.

18. Akkayan B, Gülmez T. Resistance to fracture of endodontically treated teeth restored with different post systems. The Journal of prosthetic dentistry. 2002; 87(4):431-7.

19. Torabi K, Fattahi F. Fracture resistance of endodontically treated teeth restored by different FRC posts: an in vitro study. Indian Journal of Dental Research. 2009; 20(3):282.

20. Kaur J, Sharma N, Singh H. In vitro evaluation of glass fiber post. Journal of clinical and experimental dentistry. 2012; 4(4):e204.

21. Pasqualin FH, Giovani AR, Sousa Neto MDd, Paulino SM, Vansan LP. In vitro fracture resistance of glassfiber and cast metal posts with different designs. Revista Odonto Ciência. 2012; 27(1):52-7.
22. Goodacre CJ, Spolnik KJ. The prosthodontic management of endodontically treated teeth: a literature review. Part I. Success and failure data, treatment concepts. Journal of prosthodontics: official Journal of the American College of Prosthodontists. 1994; 3(4):243-50.

23. Abduljabbar T, Sherfudhin H, AlSaleh S, Al-Helal AA, Al-Orini SS, Al-Aql NA. Fracture resistance of three post and core systems in endodontically treated teeth restored with all-ceramic crowns. King Saud University Journal of Dental Sciences. 2012; 3(1):33-8.

24. Makdad Chakmakchi RRaRS. In Vitro Comparative Assessment of Facture Resistance of Roots Restored With Everstick Fiber Reinforced Composite Post. Journal of Oral and Dental Research 2015; 2(1):43-50.

25. Martinez-Insua A, Da Silva L, Rilo B, Santana U. Comparison of the fracture resistances of pulpless teeth restored with a cast post and core or carbon-fiber post with a composite core. The Journal of prosthetic dentistry. 1998; 80(5):527-32.

26. Dean JP, Jeansonne BG, Sarkar N. In vitro evaluation of a carbon fiber post. Journal of Endodontics. 1998; 24(12):807-10.

27. Sirimai S, Riis DN, Morgano SM. An in vitro study of the fracture resistance and the incidence of vertical root fracture of pulpless teeth restored with six post-and-core systems. The Journal of prosthetic dentistry. 1999; 81(3):262-9.

\section{How to cite this article:}

Neena Chandran et al.2017, A Comparative Evaluation of Fracture Resistance of Endodontically Treated Teeth Restored With Three Different Post And Core Systems And Two Different Luting Agents-An Invitro Study. Int J Recent Sci Res. 8(5), pp. 17087-17091. DOI: http://dx.doi.org/10.24327/ijrsr.2017.0805.0279 